\title{
Non-invasive versus invasive respiratory support in preterm infants at birth: systematic review and meta-analysis
}

The authors of this Research paper (BMJ 2013;347:f5980, doi:10.1136/bmj.f5980) have informed us that during the revisions process for their manuscript they made some unintentional errors in the entry and calculation of their data. These errors require some corrections, which are listed below, but the authors state that none of the conclusions of their study have been altered by these revisions.

In both the results section of the abstract and the second paragraph of the long results section, the authors note that a reduction of bronchopulmonary dysplasia occurred with borderline significance in favour of the nasal continuous positive airway pressure (CPAP) group. However the relative risk should have been recorded as: " 0.91 (95\% confidence interval 0.81 to 1.01 ), risk difference -0.03 ( $95 \%$ confidence interval -0.07 to 0.00)."

In the results section of the abstract, the relative risk of death at 36 weeks corrected gestation should have read $0.84(95 \%$ confidence interval 0.68 to 1.04$)$, risk difference -0.02 (95\% confidence interval -0.04 to 0.01 ).
Also, in both the results section of the abstract and the second paragraph of the long results section, the authors conclude: "Pooled analysis showed a significant benefit for the combined outcome of death or bronchopulmonary dysplasia, or both, at 36 weeks corrected gestation for babies treated with nasal CPAP." However, the relative risk should have read: " 0.90 (95\% confidence interval 0.83 to 0.98$)$, risk difference -0.04 (95\% confidence interval -0.08 to -0.00 ), NNT of 25 ."

In table 3, the first three rows ("Death at 36 weeks corrected gestation," "BPD at 36 weeks corrected gestation," and "Death or BPD, or both") contain some errors and have been republished with their correct values below. This incorrect table also appeared in the print version, which can be viewed online in the "Section PDF."

Lastly, figure 2 also contains some inaccuracies and has been republished below.

Cite this as: BMJ 2014;348:g58

๑ BMJ Publishing Group Ltd 2014 


\section{Table}

Table 3 [Corrected version of first three rows]| Results of primary and secondary outcomes. Values are numbers of participants unless stated otherwise

\begin{tabular}{|c|c|c|c|c|c|c|}
\hline Variables & $\begin{array}{l}\text { No of studies } \\
\text { (references) }\end{array}$ & Nasal CPAP group & Intubation group & Relative risk (95\% Cl) & Risk difference $(95 \% \mathrm{Cl})$ & $\begin{array}{c}\text { Number needed } \\
\text { to treat }\end{array}$ \\
\hline $\begin{array}{l}\text { Death at } 36 \text { weeks } \\
\text { corrected gestation }\end{array}$ & $4^{7-10}$ & $134 / 1296$ & $171 / 1486$ & $0.84(0.68$ to 1.04$)$ & $-0.02(-0.04$ to 0.01$)$ & \\
\hline $\begin{array}{l}\text { BPD at } 36 \text { weeks corrected } \\
\text { gestation }\end{array}$ & $4^{7-10}$ & $387 / 1173$ & $465 / 1324$ & $0.91(0.81$ to 1.01$)$ & $-0.03(-0.07$ to 0.00$)$ & \\
\hline Death or BPD, or both & $4^{7-10}$ & $521 / 1296$ & $636 / 1486$ & $0.90(0.83$ to 0.98$)$ & $-0.04(-0.08$ to -0.00$)$ & 25 \\
\hline
\end{tabular}

$\mathrm{CPAP}=$ continuous positive airway pressure; $\mathrm{BPD}=$ bronchopulmonary dysplasia. 


\section{Figure}

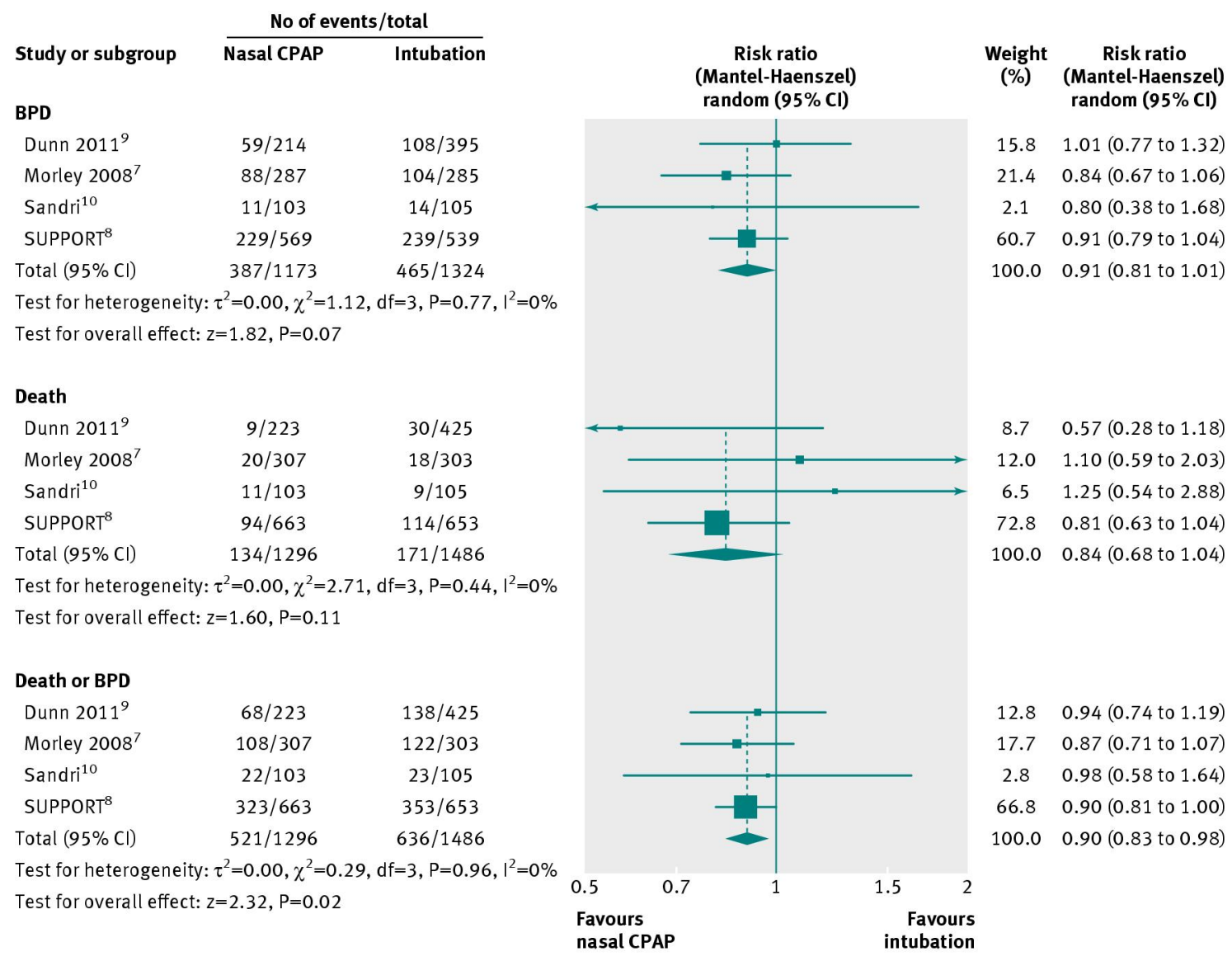

